Article

\title{
Preparation and Drug-Loading Properties of Amphoteric Cassava Starch Nanoparticles
}

\author{
Xinling Xie, Youquan Zhang *, Yong Zhu and Yiling Lan
}

Citation: Xie, X.; Zhang, Y.; Zhu, Y.; Lan, Y. Preparation and DrugLoading Properties of Amphoteric Cassava Starch Nanoparticles. Nanomaterials 2022, 12, 598. https:// doi.org/10.3390/nano12040598

Academic Editor: Simon Freakley

Received: 13 January 2022

Accepted: 8 February 2022

Published: 10 February 2022

Publisher's Note: MDPI stays neutral with regard to jurisdictional claims in published maps and institutional affiliations.

Copyright: () 2022 by the authors. Licensee MDPI, Basel, Switzerland. This article is an open access article distributed under the terms and conditions of the Creative Commons Attribution (CC BY) license (https:// creativecommons.org/licenses/by/ $4.0 /)$.

\author{
Guangxi Key Laboratory of Petrochemical Resource Processing and Process Intensification Technology, \\ School of Chemistry and Chemical Engineering, Guangxi University, Nanning 530004, China; \\ xiexinling@126.com (X.X.); zhuyongty@163.com (Y.Z.); lanyiling1996@163.com (Y.L.) \\ * Correspondence: zhangyq@gxu.edu.cn
}

\begin{abstract}
Based on the characteristics of charge reversal around the isoelectric point ( $\mathrm{pI}$ ) of amphoteric starch-containing anionic and cationic groups, amphoteric cassava starch nanoparticles (CA-CANPs) are prepared by a W/O microemulsion crosslinking method using (3-chloro-2-hydroxypropyl) trimethyl ammonium chloride as a cationic reagent and $\mathrm{POCl}_{3}$ as an anionic reagent, and the effects of preparation conditions on the particle size of the CA-CANPs are studied in detail in the present study. CA-CANPs with a smooth surface and an average diameter of $252 \mathrm{~nm}$ are successfully prepared at the following optimised conditions: a crosslinking agent amount of $15 w t \%$, an aqueous starch concentration of $6.0 w t \%$, an oil-water ratio of 10:1, a total surfactant amount of $0.20 \mathrm{~g} \cdot \mathrm{mL}^{-1}$, and a CHPTAC amount of $4.05 \mathrm{wt} \%$. The $\mathrm{pH}$-responsive value of the CA-CANPs can be regulated by adjusting the nitrogen-phosphorus molar ratio in the CA-CANPs. By using CA-CANPs with a pI of 6.89 as drug carriers and the paclitaxel (PTX) as a model drug, the maximum loading rate of $36.14 \mathrm{mg} \cdot \mathrm{g}^{-1}$ is achieved, and the loading process is consistent with the Langmuir isotherm adsorption, with the calculated thermodynamic parameters of $\Delta H^{\circ}=-37.91 \mathrm{~kJ} \cdot \mathrm{mol}^{-1}$, $\Delta S^{\circ}=-10.96 \mathrm{~J} \cdot \mathrm{mol}^{-1} \cdot \mathrm{K}^{-1}$ and $\Delta G^{\circ}<0$. By testing the release rate in vitro, it is noted that the release rates of PTX in a neutral environment $(37.6 \%$ after $96 \mathrm{~h})$ and a slightly acidic environment $(58.65 \%$ after $96 \mathrm{~h}$ ) are quite different, suggesting that the CA-CANPs have the possibility of being a targeted controlled-release carrier with $\mathrm{pH}$ responsiveness for antitumor drugs.
\end{abstract}

Keywords: cassava starch; W/O microemulsion; amphoteric starch nanoparticles; $\mathrm{pH}$-responsive; drug carrier

\section{Introduction}

Starch nanoparticles have a unique size and interface effect in addition to their good biodegradability, biocompatibility, and safety [1-3]. They have currently gained widespread use in plastic fillers, implant materials, food additives, food flavor adhesives, biodegradable composite materials, coating adhesives, and emulsion stabilizers [4-9].

In recent decades, starch nanoparticles have been used as drug carriers to load ciprofloxacin [10] and diclofenac sodium [11]. The loading capacity and the ability to penetrate biological barriers have been improved, and problems such as the high crystallinity induced by the acid hydrolysis and the high water solubility have been solved. However, these starch nanoparticles had no targeting performance, the drugs were released rapidly during blood transport, and few drug molecules could reach the focus region. Furthermore, glycolysis in tumor cells results in the secretion of large amounts of lactic acid on the plasma membrane, leading to a negative charge on the surface of cancer cells and decrease in $\mathrm{pH}$ value in the cancer cells [12]. In particular, the $\mathrm{pH}$ values of the lysosome and endosome in cancer cells usually decrease to approximately 5-6 [13]. Drug carriers with amphoteric characteristics can realize the charge reversal function through a $\mathrm{pH}$ response at the isoelectric point (PI) [14-16]; thus, they can maintain a negative charge in the blood 
to prolong the blood circulation time of the drug carrier [17]. While near tumor cells, the charge of drug carriers reverses and presents a positive charge, which is easily captured and aggregated by tumor cells [18]. It is expected that the drug carriers with amphoteric characteristics will perform good targeting functions [14].

Some amino acids and proteins have been used to modify starch into amphoteric nanoparticles as targeted drug carriers. For instance, a $\mathrm{pH}$-responsive starch nanoparticle drug carrier with a disulfide bond as the reducing sensitive group was prepared with $\mathrm{N}, \mathrm{N}$-diacrylcystamine as a crosslinking agent. After the drug was transported to tumor cells, the disulfide bond in starch nanoparticles was broken, and the drug was released to tumor cells [19]. The corn starch nanoparticle drug carrier for loading insulin was prepared by the ethanol precipitation method and using poly (L-glutamic acid) as the response group [20]. The multilayers of the highbranched cationic and linear cationic starches combined with the whey protein concentrate were constructed for post-loading thocyaninsare [21]. However, as the ratio of carboxyl and amino groups on amino acids or proteins is constant, the isoelectric point cannot be adjusted and the optional amino acids or proteins suitable for the $\mathrm{pH}$ variation characteristics of the tumor cell microenvironment are limited. In comparison, amphoteric starches can be easily prepared by introducing cationic groups and anionic groups together. The typical method is to introduce quaternary ammonium cationic groups and phosphate or carboxylic acid anionic groups. The preparation method is simple, and these groups have been successfully used in papermaking, heavy metal and dye wastewater treatment [22-26]. However, there are few reports on the kind of amphoteric starch nanoparticles as targeted drug carriers for loading chemotherapeutic drugs. Moreover, during the preparation of amphoteric starch nanoparticles, by controlling the ratio of anions and cations, the isoelectric points of amphoteric starch nanoparticles can be flexibly adjusted to be suitable for the $\mathrm{pH}$ variation characteristics of the tumor cell microenvironment and realize the targeting function with $\mathrm{pH}$-responsive charge reversal.

In the present study, by using cassava starch as a raw material, (3-chloro-2-hydroxypropyl) trimethyl ammonium chloride (CHPTAC) as a cationic reagent, phosphorus oxychloride $\left(\mathrm{POCl}_{3}\right)$ as a crosslinking and anionic reagent, the amphoteric starch nanoparticles (CA-CANPs) were prepared by a W/O microemulsion-crosslinking method. The paclitaxel (PTX) was used as a model drug to investigate the drug loading and release behaviour of CA-CANPs. As expected, the isoelectric point of CA-CANPs was controllable by simply adjusting the ratio of anions and cations; the lower crystallinity of CA-CANPs promotes the drug to be loaded inside nanoparticles, thus improving the drug loading capacity and showing good slow-release performance in a normal body fluid environment. Unstable phospholipid bond hydrolysis under acidic conditions promotes the disintegration of the drug carrier to meet the requirements of faster drug release in a slightly acidic environment.

\section{Materials and Methods}

\subsection{Materials}

Food-grade native cassava starch was obtained from Guangxi Napo Jinyuan Starch Co., Ltd. (Nanning, China). (3-Chloro-2-hydroxypropyl) trimethyl ammonium chloride (CHPTAC) (60 wt\%), Span80, and Tween60 were purchased from Shanghai McLean Biochemical Technology Co., Ltd. (Shanghai, China). Cyclohexane and sodium hydroxide were supplied by Guangdong Guanghua Technology Co., Ltd. (Guangzhou, China). $\mathrm{POCl}_{3}$ was purchased from Sinopharm Chemical Reagents Co., Ltd. (Shanghai, China). Anhydrous ethanol and $\mathrm{HCl}$ were obtained from Chengdu Kelong Chemicals Co., Ltd. (Chengdu, China). Paclitaxel (PTX) was supplied by Aladdin Reagents Co., Ltd. (Shanghai, China). All chemicals were analytical grade and used without further purification. Deionized water was used throughout the work. 


\subsection{Preparation of Amphoteric Cassava Starch Nanoparticles}

\subsubsection{Pretreatment of Cassava Starch by Acid Hydrolysis}

A $10 w t \%$ cassava starch suspension was prepared from raw cassava starch and $2.2 \mathrm{~mol} / \mathrm{L} \mathrm{HCl}$ solution. The starch suspension was placed into a $40{ }^{\circ} \mathrm{C}$ water bath and stirred for 1-72 h; subsequently, the suspension was filtered and washed with deionized water until neutral $(\mathrm{pH}=7)$, and the acid-treated cassava starch granules were obtained by drying in air at $60^{\circ} \mathrm{C}$ for $24 \mathrm{~h} \mathrm{[27].}$

\subsubsection{Preparation of Amphoteric Cassava Starch Nanoparticles (CA-CSNPs)}

CA-CSNPs were prepared by a W/O microemulsion-crosslinking method: cyclohexane was used as the oil phase, Span 80 and Tween 60 were used as surfactants, acid-treated cassava starch was used as the raw material, CHPTAC was used as a cationic reagent, and $\mathrm{POCl}_{3}$ was used as a crosslinking agent and anionic reagent. First, the $\mathrm{pH}$ value of the acid-treated cassava starch suspension (2-10 wt\%) was adjusted to $11.5 \sim 12.0$ by using a $1.0 \mathrm{~mol} / \mathrm{L} \mathrm{NaOH}$ water solution, and was gelatinized in a boiling water bath for $40 \mathrm{~min}$ to obtain a cassava starch gelatinization solution. Second, the oil phase was prepared by dissolving a 1.0-30.0 g mixture of Span 80 and Tween 60 (Span 80/Tween $60=3: 7 \sim 9: 1(w / w)$ ) in $100 \mathrm{~mL}$ cyclohexane and maintained at $40{ }^{\circ} \mathrm{C}$. Third, at continuous $500 \mathrm{r} / \mathrm{min}$ stirring, $5-25 \mathrm{~mL}$ of cassava starch gelatinization solution, used as the aqueous phase, was added slowly into the oil phase, and further stirred at $1600 \mathrm{r} / \mathrm{min}$ for $1 \mathrm{~h}$ to obtain a microemulsion. Subsequently, 3.6-4.2 $w t \%$ (based on the cassava starch mass) CHPTAC and 5-25 wt $\%$ (based on the cassava starch mass) $\mathrm{POCl}_{3}$ were added to the microemulsion and reacted at $40{ }^{\circ} \mathrm{C}$ for $2 \mathrm{~h}$ with stirring at $1600 \mathrm{r} / \mathrm{min}$ to obtain the CA-CSNPs microemulsion. Then, the CA-CSNPs microemulsion was demulsified with ethanol and centrifuged at 12,000 r/min with a 5810R centrifuge (Eppendorf, Hamburg, Germany) to obtain the precipitates of the CA-CSNPs. The precipitates were acidified for $0.5 \mathrm{~h}$ with $0.2 \mathrm{~mol} / \mathrm{L} \mathrm{HCl}$ and alternately washed with ethanol and ionized water, and the CA-CSNPs were obtained by drying in a vacuum dryer for $5 \mathrm{~h}$ at $35^{\circ} \mathrm{C}$.

\subsection{Characterization}

The nitrogen content $(N \%, w / w)$ in the CA-CSNPs was determined by an automatic elemental analyzer (Elementar Analysen System, Langenselbold, Germany), and the phosphorus content $(P \%, w / w)$ in the CA-CSNPs was determined by ammonium molybdatecolorimetry as described in the literature [28]. The molar ratio of nitrogen to phosphorus $\left(r_{N / P}\right)$ was calculated by Equation (1).

$$
r_{N / P}=\frac{31 \times N \%}{14 \times P \%}
$$

where, $r_{N / P}$ is the molar ratio of nitrogen to phosphorus in the CA-CSNPs; $N \%$ is the nitrogen content in the CA-CSNPs, $w t \% ; P \%$ is the phosphorus content in the CA-CSNPs, $w t \%) ; 14$ is the atomic weight of nitrogen; and 31 is the atomic weight of phosphorus.

The morphologies and particle size of native cassava starch, acid-hydrolyzed starch, and CA-CSNPs were characterized by field emission scanning electron microscopy (FESEM, Hitachi SU8220, Tokyo, Japan) at an accelerating voltage of $5 \mathrm{kV}$. The surface groups on the samples were determined by Spectrum 100 Fourier transform infrared spectroscopy (Perkin Elmer, Waltham, MA, USA). The solid-state ${ }^{13} \mathrm{C}$ NMR spectra of the sample after ultrasound treatment for 5 min were obtained by a Bruker AVANCE III 400 HD spectrometer. X-ray powder diffraction (XRD) analysis was performed on a DX-2700A X-ray diffractometer (Rigaku Corporation, Tokyo, Japan) with $40 \mathrm{kV}$ radiation and $30 \mathrm{~mA}$ radiation. The average particle size and zeta potential of CA-CSNPs were determined by a Nano-ZS90X laser particle analyzer (Malvern, UK). 


\subsection{Drug Loading and Release on CA-CSNPS}

The drug-loading rate of CA-CSNPs was examined using PTX as a model drug. The drug-loading experiment was conducted in the following procedure: $100 \mathrm{mg}$ CA-CSNPs ( $\mathrm{pI}=6.89$ ) and 2-8 $\mathrm{mg}$ PTX were suspended in 50 mL 50-100 $w t \%$ ethanol aqueous solvent and stirred at $300 \mathrm{r} / \mathrm{min}$ at $20-40{ }^{\circ} \mathrm{C}$ for $0-420 \mathrm{~min}$. Subsequently, the suspension was centrifuged, and the PTX concentration of the liquid supernatant was determined by a $\mathrm{UV}-$ vis spectrophotometer at $230 \mathrm{~nm}$. The drug loading rate $\left(\mathrm{mg} \cdot \mathrm{g}^{-1}\right)$ and encapsulation efficiency (\%) were calculated by Equations (2) and (3), respectively.

The drug-releasing experiment was conducted in the following procedure: $90 \mathrm{mg}$ drug-loaded CA-CSNPs with a PTX loading rate of $36.14 \mathrm{mg} \cdot \mathrm{g}^{-1}$ and $3.20 \mathrm{mg}$ free PTX were added to the dialysis bag respectively, and $10 \mathrm{~mL}$ normal saline was added into the dialysis bag. Subsequently, the dialysis bag was placed in a beaker containing $40 \mathrm{~mL}$ normal saline and vibrated in a shaker at $37^{\circ} \mathrm{C}$. At an interval of $0-300 \mathrm{~min}, 40 \mathrm{~mL}$ of the solution was removed from the beaker, and the PTX concentration in normal saline was determined by using a UV-vis spectrophotometer at $230 \mathrm{~nm}$. At the same time, $40 \mathrm{~mL}$ fresh normal saline was supplied to keep the volume constant. The cumulative release rate of the drug was calculated by Equation (4).

$$
\begin{gathered}
q=\frac{\left(C_{0}-C_{1}\right) \times V_{0}}{m_{0}} \\
y=\frac{\left(C_{0}-C_{1}\right) \times V_{0}}{C_{0} \times V_{0}} \times 100 \\
\eta_{\mathrm{d}}=\frac{m_{c}}{m_{1} \times q_{0}} \times 100
\end{gathered}
$$

where, $q$ is the loading rate of CA-CSNPs to PTX, $\mathrm{mg} \cdot \mathrm{g}^{-1} ; y$ is the encapsulation efficiency of PTX, \%; $\eta_{\mathrm{d}}$ is the cumulative release rate of PTX, $\% ; C_{0}$ is the initial concentration of PTX solution, $\mathrm{mg} \cdot \mathrm{mL}^{-1} ; C_{1}$ is the residual concentration of PTX solution, $\mathrm{mg} \cdot \mathrm{mL}^{-1} ; V_{0}$ is the volume of PTX solution, $\mathrm{mL} ; m_{0}$ is the mass of CA-CSNPs, $\mathrm{g} ; m_{1}$ is the mass of CA-CSNPs including loaded PTX, $\mathrm{g} ; m_{\mathrm{C}}$ is the cumulative desorption amount of PTX, $\mathrm{mg}$; and $q_{0}$ is the initial load rate of PTX on the CA-CSNPs, $\mathrm{mg} \cdot \mathrm{g}^{-1}$.

\section{Results}

\subsection{Pretreatment of Cassava Starch by Acid Hydrolysis}

The effects of acid hydrolysis time on the molecular weight of acid-treated starch and the size and yield of CA-CSNPs are shown in Table 1.

\begin{tabular}{|c|c|c|c|}
\hline $\begin{array}{l}\text { Acid Hydrolysis } \\
\text { Time (h) }\end{array}$ & $\begin{array}{c}\text { Starch Molecular } \\
\text { Weight }\left(\mathbf{1 0}^{3} \mathrm{~g} \cdot \mathrm{mol}^{-1}\right)\end{array}$ & Diameter (nm) & Yield (\%) \\
\hline 0 & 3708.20 & $869.5 \pm 25.1$ & 57.78 \\
\hline 1 & 2034.48 & $652.2 \pm 10.5$ & 79.64 \\
\hline 4 & 392.51 & $552.7 \pm 6.1$ & 81.00 \\
\hline 8 & 69.31 & $382.1 \pm 6.5$ & 82.88 \\
\hline 12 & 37.28 & $403.8 \pm 9.1$ & 83.12 \\
\hline 24 & 8.71 & $306.9 \pm 11.6$ & 85.12 \\
\hline 48 & 6.60 & $241.6 \pm 3.6$ & 88.60 \\
\hline 72 & 5.32 & $263.0 \pm 10.5$ & 88.58 \\
\hline
\end{tabular}

Table 1. Effects of acid hydrolysis time on the molecular weight of acid-treated starch and the size and yield of CA-CSNPs.

Cassava starch has the second-largest molecular weight (only smaller than potato starch) among natural starches, which has a high viscosity of the starch paste. A large number of sticky walls will be found when preparing the $\mathrm{W} / \mathrm{O}$ microemulsions by using cassava starch, which exhibit a low yield and poor operability. After acid hydrolysis, the 
molecular weight of cassava starch is reduced, which will greatly alleviate or eliminate wall adhesion. As shown in Table 1, the starch molecular weight, particle size, and yield of CA-CSNPs are significantly affected by the acid hydrolysis time. It was found that cassava starch obtained after $48 \mathrm{~h}$ of acid hydrolysis exhibits a distinctly low molecular weight and a small CA-CSNP particle size, which could effectively overcome the wall adhesion phenomenon in the microemulsification process, leading to an increase in the yield to more than $88 \%$, so the product of acid hydrolysis after $48 \mathrm{~h}$ is used for further synthesis.

\subsection{Optimization for The Preparation of CA-CSNPS}

The effects of preparation conditions on the particle size and the polydispersity index (PDI) of CA-CSNPs were studied in detail, and are shown in Figure 1. To make it clearly, we would like to discuss them separately.
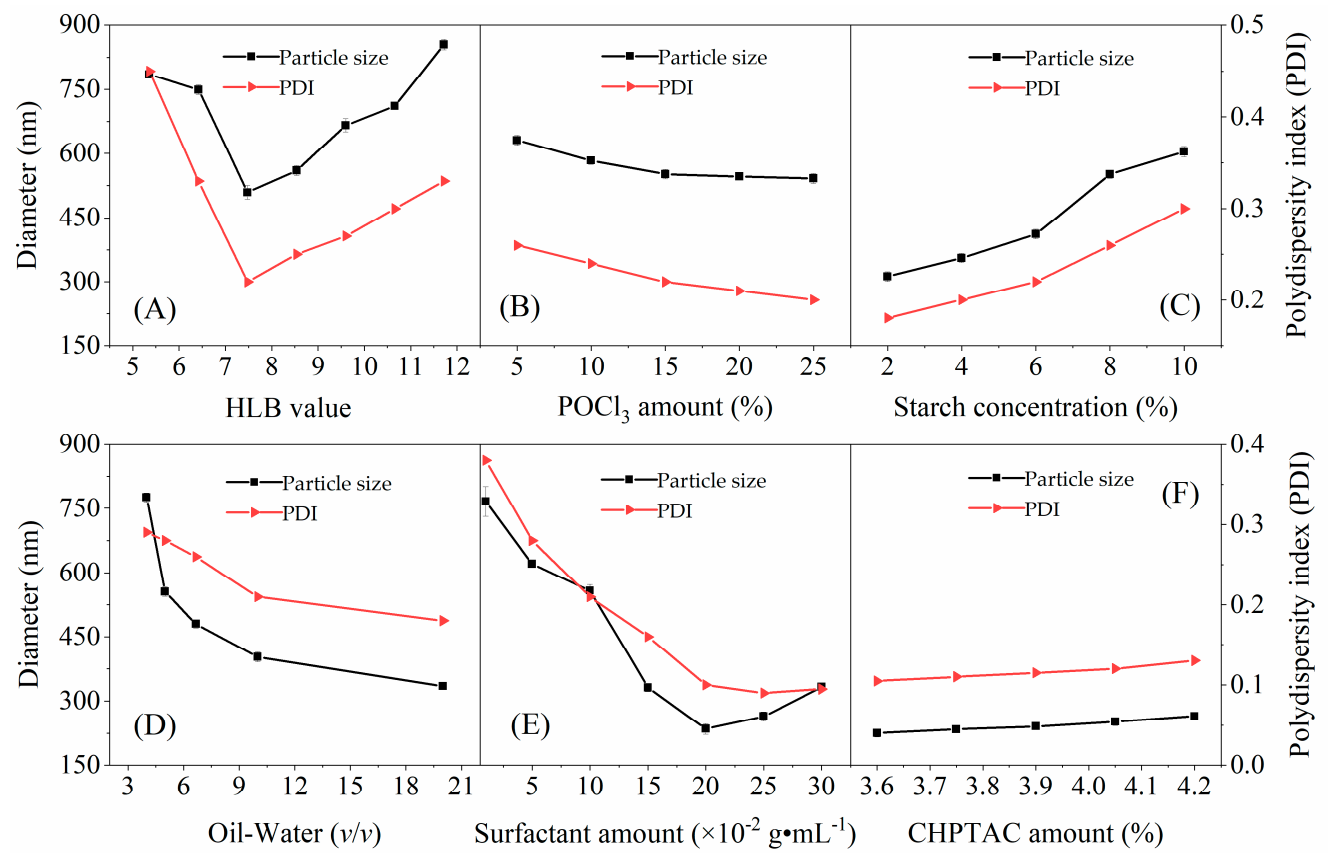

Figure 1. Effects of (A) $\mathrm{HLB}$ value (at a $\mathrm{POCl}_{3}$ amount of $15 w t \%$, an aqueous starch concentration of $6.0 w t \%$, an oil-water ratio of 10:1 (v/v), a surfactants total amount of $0.15 \mathrm{~g} \cdot \mathrm{mL}^{-1}$, and a CHPTAC amount of $3.9 w t \%)$; (B) $\mathrm{POCl}_{3}$ amount (at a HLB value of 7.48, an aqueous starch concentration of $6.0 w t \%$, an oil-water ratio of 10:1 (v/v), a surfactants total amount of $0.15 \mathrm{~g} \cdot \mathrm{mL}^{-1}$, and a CHPTAC amount of $3.9 w t \%$ ); (C) starch concentration (at a HLB value of 7.48, a $\mathrm{POCl}_{3}$ amount of $15 w t \%$, an oil-water ratio of $10: 1(\mathrm{v} / \mathrm{v})$, a surfactants total amount of $0.15 \mathrm{~g} \cdot \mathrm{mL}^{-1}$, and a CHPTAC amount of $3.9 w t \%$ ); (D) oil-water ratio (at a HLB value of 7.48, a $\mathrm{POCl}_{3}$ amount of $15 w t \%$, an aqueous starch concentration of $6.0 w t \%$, a surfactants total amount of $0.15 \mathrm{~g} \cdot \mathrm{mL}^{-1}$, and a CHPTAC amount of $3.9 w t \%$ ); (E) surfactant amount(at a HLB value of 7.48, a $\mathrm{POCl}_{3}$ amount of $15 w t \%$, an aqueous starch concentration of $6.0 w t \%$, an oil-water ratio of 10:1 (v/v), and a CHPTAC amount of $3.9 w t \%)$; (F) CHPTAC amount (at a HLB value of 7.48, a $\mathrm{POCl}_{3}$ amount of $15 w t \%$, an aqueous starch concentration of $6.0 \mathrm{w} \%$, an oil-water ratio of 10:1 (v/v), and a total surfactants amount of $0.20 \mathrm{~g} \cdot \mathrm{mL}^{-1}$ ) on the CA-CSNPs particle size and the polydispersity index (PDI). All reactions were performed at $40{ }^{\circ} \mathrm{C}$ for $2 \mathrm{~h}$.

As shown in Figure 1A, when the hydrophilic-lipophilic balance (HLB) value of surfactants was lower than seven, the surfactants were highly lipophilic, and the system became turbid or milky, failing to form a microemulsion. When the HLB value was gradually increased to 7.48, the system gradually changed from milky to translucent or transparent and formed a stable microemulsion. As a result, the average diameter of the CA-CSNPs reached the smallest value of $508 \mathrm{~nm}$. When the HLB value exceeded 7.48 and increased to 11.6, a clear and transparent state of the microemulsion was also found; 
however, the microemulsion system became glassy glue, with high viscosity and poor fluidity, resulting in a larger size. Therefore, the optimal HLB value for preparing the CA-CSNPs was 7.48 .

As shown in Figure 1B, when the amount of crosslinking agent $\left(\mathrm{POCl}_{3}\right)$ is increased from 5.0 to $25 \%$, the average diameter of CA-CSNPs gradually decreases from 640 to $550 \mathrm{~nm}$. The observation can be explained as following: with the increase in the amount of crosslinking agent, the crosslinking density of the molecular chains in the CA-CSNPs increase and the molecular arrangement is always compact, resulting in a reduction in the particle size of the CA-CSNPs.

Figure $1 \mathrm{C}$ shows that the particle size of CA-CSNPs increases significantly with the increase in starch concentration. This is due to the fact that the higher starch concentration in individual microemulsion micelles would lead to a decrease in the crosslinking density. In this case, the starch molecular chains are loosely arranged, resulting in larger particles. When the starch concentration decreases from 10 to $6 \%$, the average diameter of CA-CSNPs decreases correspondingly from 603 to $396 \mathrm{~nm}$; when the starch concentration decreases from 6 to $2 \%$, the average diameter of CA-CSNPs changes insignificantly from 396 to $326 \mathrm{~nm}$. However, the yield of CA-CSNPs at the starch concentration of $6 \%$ was approximately three times higher than that at $2 \%$. Therefore, the selective starch concentration for preparing the CA-CSNPs was $6 \%$.

As shown in Figure 1D, when the oil-water ratio increases from 4 to 10, the average diameter of the CA-CSNPs decreases dramatically from 775 to $402 \mathrm{~nm}$. With the increase in the oil-water ratio, the water phase surface area per unit would obtain more surfactants, thus the interfacial tension would be reduced, making it easy to form smaller droplets. This would eventually lead to a decrease in particle size [29]. However, when the oil-water ratio reaches to 12.5, an insignificant decrease in particle size is observed since the surfactant occupies the optimal proportion at the oil-water interface [30]. Therefore, the selective oil-water ratio for preparing the CA-CSNPs was 10:1.

Figure 1E shows that the particle size of CA-CSNPs decreases when the surfactant amount increases from 0.01 to $0.2 \mathrm{~g} \cdot \mathrm{mL}^{-1}$. However, an overfull surfactant $\left(>0.2 \mathrm{~g} \cdot \mathrm{mL}^{-1}\right)$ would form a large number of empty micelles [31], which would trap $\mathrm{POCl}_{3}$ molecules and block them to contact the starch molecules effectively, resulting in low crosslinking density and large particle size. Therefore, the optimal surfactant amount for further study was chosen as $0.2 \mathrm{~g} \cdot \mathrm{mL}^{-1}$.

As shown in Figure 1F, when the CHPTAC amount increases from 3.60 to $4.20 \%$, the particle size shows a slightly increasing trend. Since the cationic and anionic reactions are two competitive reaction processes in a crosslinking reaction, some reactive active sites, i.e., the -OH groups, are occupied by cationic groups, resulting in the decrease in the number of active sites functionalized with the crosslinking agent, and thus the decrease in crosslinking density and a slight increase in particle size.

As for the conditions influencing the PDI of CA-CSNPs, it is shown that the key factors for the formation of the $\mathrm{W} / \mathrm{O}$ microemulsion, i.e., the ratio of oil to water, HLB value, and the amount of the surfactants, have great influence on the particle size distribution, while the starch concentration, the amount of crosslinking agent, and the amount of CHPTAC have little effect on the particle size distribution. Under the optimized conditions, i.e., the HLB value of 7.48, crosslinking agent amount of $15 w t \%$, aqueous starch concentration of $6.0 w t \%$, oil-water ratio of $10: 1$, surfactants total amount of $0.20 \mathrm{~g} \cdot \mathrm{mL}^{-1}$, and CHPTAC amount of $4.05 w t \%$, the obtained CA-CSNPs had a smaller particle size and more uniform particle size distribution, which was characterized in the following and used for the drugloading properties study.

\subsection{FTIR and NMR Analysis of CA-CSNPS}

In the present work, CHPTAC provides the cationic group, while $\mathrm{POCl}_{3}$ provides anionic groups and reacts with hydroxyl groups of the cassava starch molecules in the droplets, working as a crosslinking group between starch molecules [32,33]. 
The FTIR and ${ }^{13} \mathrm{C}$ NMR spectra of native cassava starch, acid-treated cassava starch, and CA-CSNPs are shown in Figure 2A and B, respectively.
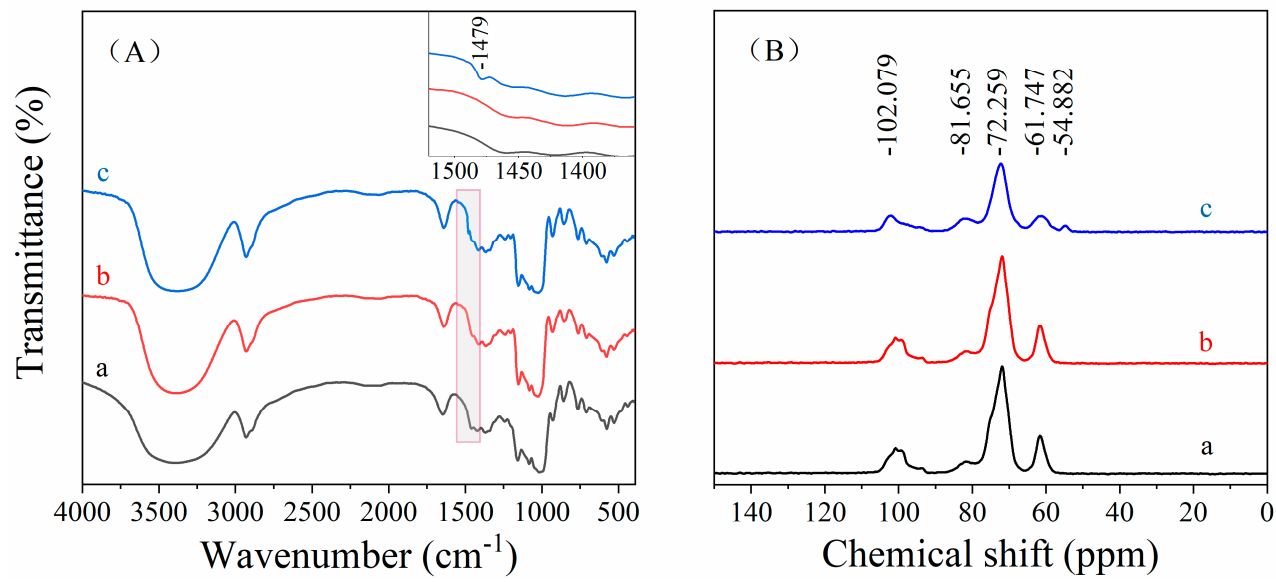

Figure 2. FTIR spectra (A) and ${ }^{13} \mathrm{C}$ NMR spectra (B) of (a) native cassava starch, (b) acid-treated cassava starch, and (c) CA-CSNPs. The inset of (A) is a partial enlargement of $(a, b$, and c).

As shown in Figure 2A, a new peak at $1479 \mathrm{~cm}^{-1}$ was found in the spectrum of CA-CSNPs (Figure 2Ac), which is attributed to the stretching vibration of $\mathrm{C}-\mathrm{H}$ from the quaternary ammonium group [26]. Theoretically, the absorption peaks of $\mathrm{P}=\mathrm{O}$ and $\mathrm{P}-\mathrm{O}$ should also appear at 1126 and $1109 \mathrm{~cm}^{-1}$ in the FTIR spectrum. However, these peaks are not distinguishable in Figure 2Ac due to the very low content of phosphorus in the samples, which could be shielded by the C-O peaks of cassava starch molecules at 1153, 1078, and $1022 \mathrm{~cm}^{-1}$ [34]. Nevertheless, a certain content of phosphorus was detected in CA-CSNPs samples (Table 2), which could be taken as evidence to prove that the crosslinking reaction has taken place between the starch molecule and $\mathrm{POCl}_{3}$.

Table 2. Effects of CHPTAC amount on the content of nitrogen and phosphorus, $r_{N / P}$, and pI of CA-CSNPs.

\begin{tabular}{|c|c|c|c|c|c|}
\hline Samples & $\begin{array}{c}\text { CHPTAC } \\
\text { Amount } \\
(w t \%)\end{array}$ & $\begin{array}{c}\text { Nitrogen } \\
\text { Content }(\%)\end{array}$ & $\begin{array}{l}\text { Phosphorus } \\
\text { Content (\%o) }\end{array}$ & $\begin{array}{c}r_{N / P} \\
\left(\mathrm{~mol} \cdot \mathrm{mol}^{-1}\right)\end{array}$ & pI \\
\hline A-1 & 0.0 & 0.0 & $4.31 \pm 0.02$ & 0.0 & - \\
\hline CA-1 & 3.60 & $0.97 \pm 0.03$ & $4.27 \pm 0.02$ & 0.50 & 4.79 \\
\hline CA-2 & 3.75 & $1.03 \pm 0.05$ & $3.96 \pm 0.03$ & 0.58 & 5.38 \\
\hline CA-3 & 3.90 & $1.20 \pm 0.01$ & $4.20 \pm 0.04$ & 0.63 & 5.95 \\
\hline CA-4 & 4.05 & $1.46 \pm 0.03$ & $3.81 \pm 0.01$ & 0.84 & 6.89 \\
\hline CA-5 & 4.20 & $1.83 \pm 0.02$ & $3.68 \pm 0.03$ & 1.10 & 10.32 \\
\hline
\end{tabular}

To further confirm the reaction between cassava starch and CHPTAC, the samples were examined using ${ }^{13} \mathrm{C}$ NMR spectroscopy, and the results are shown in Figure 2B. The ${ }^{13} \mathrm{C}$ NMR spectrum of CA-CSNPs (Figure 2Bc) shows an additional peak at $54.882 \mathrm{ppm}$, which is attributed to the carbon in the methyl group $\left(-\mathrm{CH}_{3}\right)$ [35]. Overall, these findings indicate that the cationic groups were successfully introduced in the CA-CSNPs, which is consistent with the FTIR results.

\subsection{Morphology and Crystallinity Analysis}

The SEM and XRD analysis results of native cassava starch, acid-treated cassava starch and CA-CSNPs, and the particle size distribution of CA-CSNPs are shown in Figure 3, respectively.

As shown in Figure 3A, native cassava starch particles are round-shaped, while immature cassava starches show irregular particles with particle sizes of 1 to $20 \mu \mathrm{m}$. Compared with native cassava starches, acid-treated cassava starches (Figure 3B) show 
almost the same particle size but with a rougher surface and more broken particles due to fast hydrolysis in the amorphous regions and slow hydrolysis in the crystalline regions [36]. As shown in Figure 3C,D, CA-CSNPs exhibit a smooth surface and uniform particle sizes. Figure 3E shows the results of particle size and distribution of CA-CSNPs measured by a Nano-ZS90X laser particle analyzer (DLS), and the size distribution of CA-CSNPs was relatively concentrated with a polydispersity index (PDI) of 0.12 and an average diameter of $252 \mathrm{~nm}$.
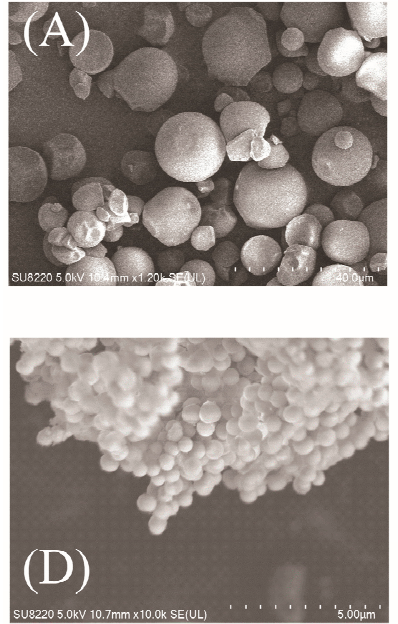
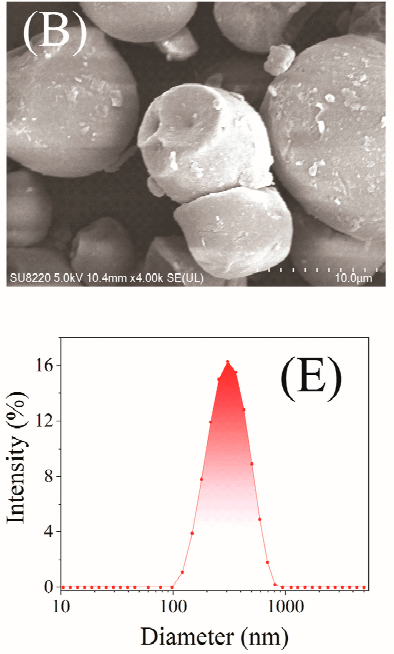
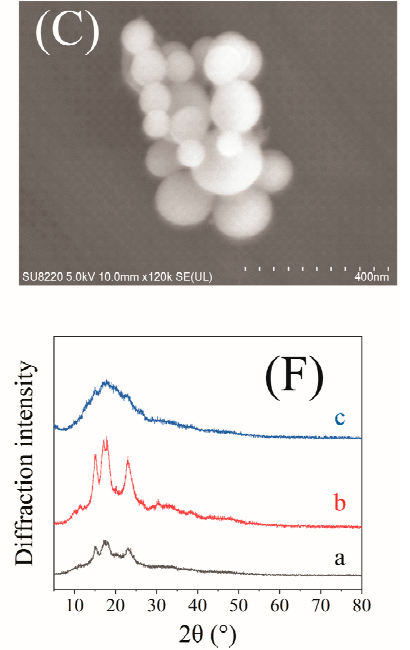

Figure 3. SEM images of (A) native cassava starch; (B) acid-treated cassava starch; (C) CA-CSNPs $(\times 120,000)$; (D) CA-CSNPs $(\times 10.000)$; and $($ E) the particle size and distribution of CA-CSNPs and the XRD patterns (F) of (a) native cassava starch; (b) acid-treated cassava starch; and (c) CA-CSNPs. (The conditions for the preparation of the CA-CSNPs were as follows: a crosslinking agent amount of $15 w t \%$, an aqueous starch concentration of $6.0 w t \%$, an oil-water ratio of 10:1 (v/v), a total surfactant amount of $0.20 \mathrm{~g} \cdot \mathrm{mL}^{-1}$, and a CHPTAC amount of $\left.4.05 w t \%\right)$.

As shown in Figure $3 \mathrm{Fa}, \mathrm{Fb}$, strong diffraction peaks were observed in the native cassava starch and the acid-treated cassava starch at $2 \theta=15,17,18$, and $23.5^{\circ}$, indicating a typical A-type crystalline structure [36,37]. The crystallinity of the native cassava starch, calculated by the full width at half maximum, was $37.05 \%$, and that of the cassava starch after $48 \mathrm{~h}$ of acid hydrolysis was $48.08 \%$, indicating that it is easier for acid hydrolysis in amorphous regions [36]. As shown in Figure 3Fc, the CA-CSNPs retain only weak diffraction peaks at $2 \theta=15^{\circ}$, and the crystallinity was less than $4.6 \%$, indicating that most of the CA-CSNPs prepared by the $\mathrm{W} / \mathrm{O}$ microemulsion crosslinking reaction had an amorphous structure.

\subsection{Thermostability Analysis}

Figure 4 shows the TGA and DTA analysis results of native cassava starch and CA-CSNPs.
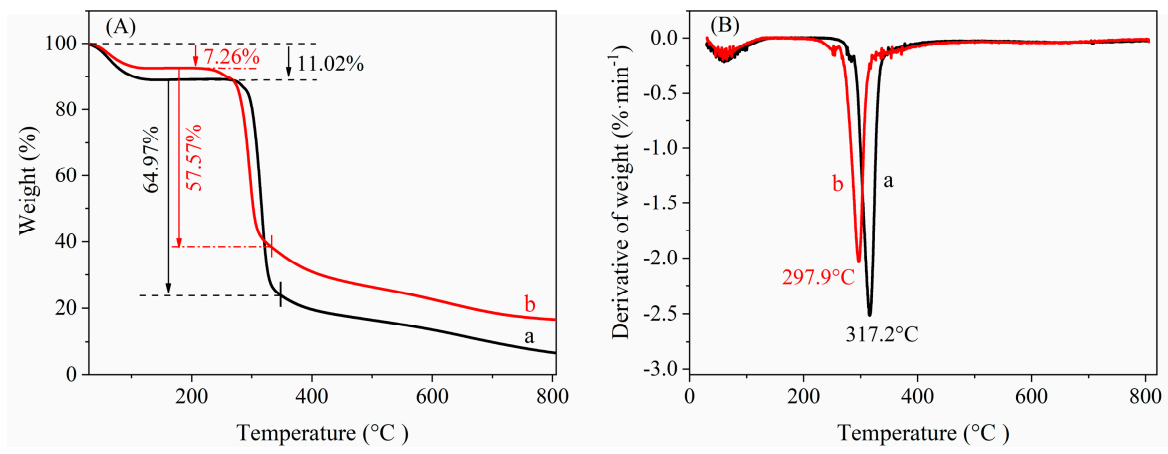

Figure 4. TGA (A) and DTA (B) of (a) native cassava starch and (b) CA-CSNPs. 
As shown in Figure 4, the maximum decomposition temperatures of native cassava starch and CA-CSNPs are 317.2 and $297.9^{\circ} \mathrm{C}$, respectively. The results indicated that the thermal stability of CA-CSNPs was only slightly decreased after acid pretreatment, crosslinking, and amphoteric modification of native cassava starch in the $\mathrm{W} / \mathrm{O}$ microemulsion.

\subsection{Surface Charge and $p H$ Response Analysis}

Figure 5A shows that the zeta potential of anionic cassava starch nanoparticles (A-1, $\left.r_{N / P}=0\right)$ is decreasing from -1.12 to $-21.37 \mathrm{mV}$ with the increasing of the $\mathrm{pH}$ value from 4 to 10 , presenting only negative charge characteristics and no isoelectric point. For CACSNPs (CA-1 CA-5), the zeta potential is also decreasing with the increase in the $\mathrm{pH}$ value from 4 to 10; however, the charge of CA-CSNPs shifts from positive to negative. Thus, the corresponding $\mathrm{pH}$ value where the zeta potential value $=0$ is the $\mathrm{pI}$ of CA-CSNPs. In the left area of the $\mathrm{pI}$ line $($ Zeta $=0)$ shown in Figure $5 \mathrm{~B}$, the zeta potential of CA-CSNPs is positive, and the CA-CSNPs present a positive charge. In the right area of the pI line, the zeta potential of CA-CSNPs is negative, and the CA-CSNPs showed a negative charge. The results indicate that the CA-CSNPs have a charge-reversal function with a $\mathrm{pH}$ response, and the $\mathrm{pH}$-responsive value $(\mathrm{pI})$ is increasing with the increase in the molar ratio of nitrogen to phosphorus. As shown in Table 2, when the molar ratio of nitrogen to phosphorus increases from 0.50 to 1.10 , the $\mathrm{pI}$ of CA-CSNPs increases from 4.79 to 10.32 , which indicates that the pI of CA-CSNPs is controllable by adjusting the molar ratio of the cationic and anionic groups on the CA-CSNPs.
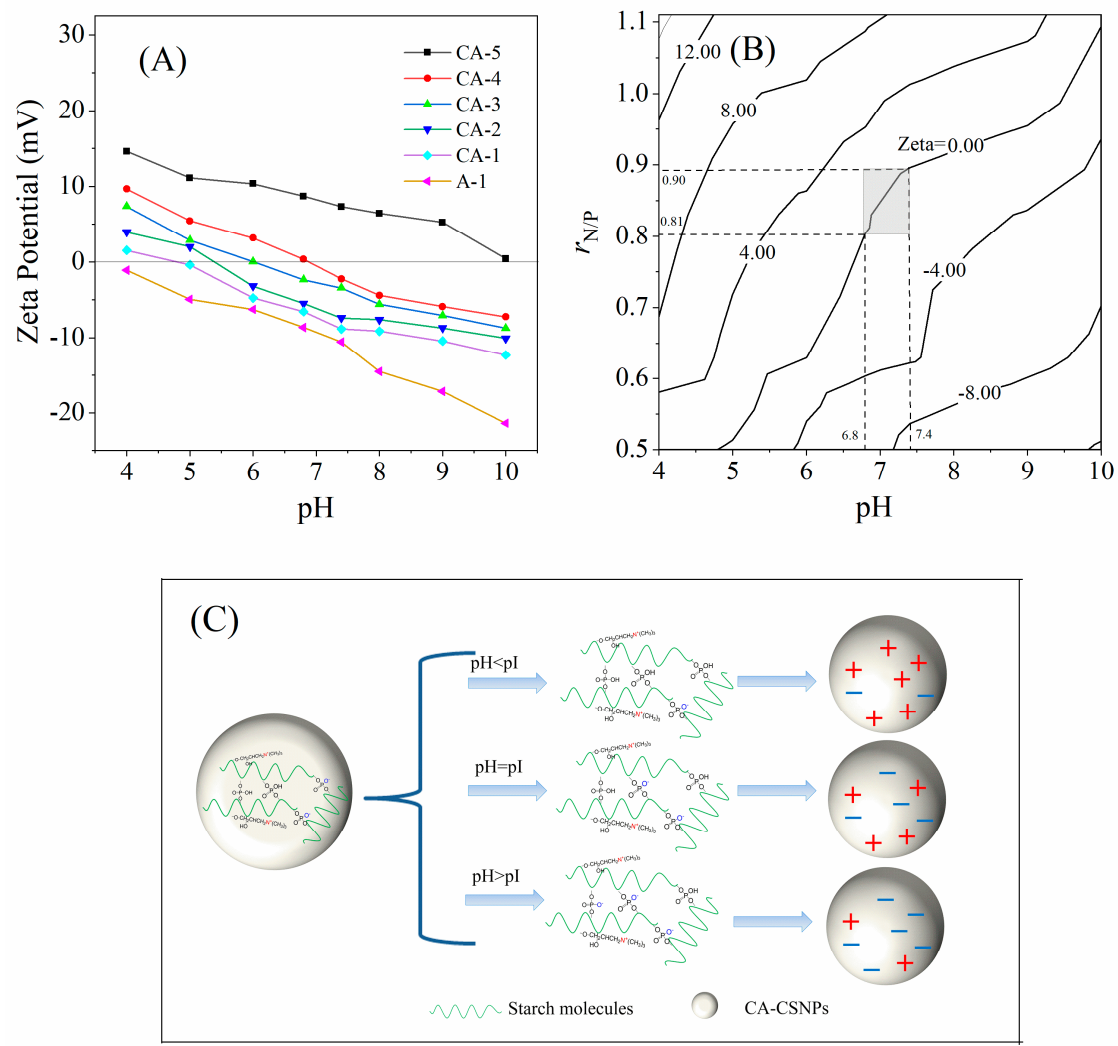

Figure 5. Effects of solution $\mathrm{pH}$ and the N/P ratio on the zeta potential (A) and isopotential map (B) of CA-CSNPs and the charge-reversal mechanism on CA-CSNPs (C).

The shaded area shown in Figure 5B indicates that the pI of CA-CSNPs could be adjusted to between 6.8 and 7.4 by controlling the $r_{N / P}$ in the range of $0.81-0.90$. Some studies have presented that the $\mathrm{pH}$ value of human blood and normal cells is approximately 7.4 , while a large amount of glycolysis in tumor cells would secrete a large amount of lactic acid on the plasma membrane of tumor cells, which would not only produce a unique 
negative charge on the surface of tumor cells but also make the $\mathrm{pH}$ of the tumor extracellular microenvironment lower than 6.8, and the $\mathrm{pH}$ value of endosomes and lysosomes in tumor cells is approximately 5-6 [12,13]. Therefore, the CA-CSNPs should act as pH-responsive drug carriers to treat tumor cells. As shown in Figure 5C, if the CA-CSNPs are in human blood or near-normal cells, the net charge on the CA-CSNPs surface exhibits a negative charge, which can be conducive to prolonging the blood circulation time of the drug carrier [17]. If the CA-CSNPs is transported to the vicinity of tumor cells, they will conduce the charge-reversal function with a $\mathrm{pH}$ response since the $\mathrm{pH}$ near the tumor cells is less than 6.8, and the net charge on the surface of CA-CSNPs shows a positive charge, which will promote the absorption capacity of the tumor cells to the drug carrier due to electrostatic attraction [38].

\subsection{Drug Loading Analysis}

Paclitaxel (PTX, $\mathrm{C}_{47} \mathrm{H}_{51} \mathrm{NO}_{14}$ ) is a natural diterpenalkaloid with anticancer activity that has been widely used in the treatment of breast cancer, ovarian cancer, some head and neck cancers, and lung cancer [39]. Free PTX in the PTX formulation is easily bound to proteins in the blood and is cleared as a foreign body by macrophages [40]. Biodegradable nanoparticles loaded with PTX as a controlled release formulation for an anticancer drug can achieve various goals, including drug targeting, improving drug availability, and protecting drug bioactivity.

The loading rate of the drug by using the adsorption-loading method is mainly affected by the type of media, the initial drug concentration, and the adsorption temperature. The effects of loading conditions on the loading rate of PTX and the fitting results of kinetic adsorption models are shown in Figure 6.

PTX has a low solubility of $30 \mathrm{mg} \cdot \mathrm{L}^{-1}$ at $25^{\circ} \mathrm{C}$ in water [41] and a high solubility of $39 \mathrm{~g} \cdot \mathrm{L}^{-1}$ at $25^{\circ} \mathrm{C}$ in ethanol [42]. As shown in Figure 6A, PTX are adsorbed better on CA-CSNPs with water and ethanol as the mixed medium, and the maximum loading rate reached $32.07 \mathrm{mg} \cdot \mathrm{g}^{-1}$ when the ethanol concentration was approximately $70 w t \%$. The adsorption of ethanol and PTX on CA-CSNPs are competitive adsorption processes; when the concentration of ethanol was less than $70 w t \%$, the solubility of PTX decreased with the increase in water content in an ethanol-water solvent, and some PXT was not dissolved [43], resulting in the initial concentration of PTX being less than $100 \mathrm{mg} \cdot \mathrm{L}^{-1}$, and the loading rate at adsorption equilibrium was lower than that of $70 w t \%$ ethanol. When the ethanol concentration was higher than $70 w t \%$, although PTX could be completely dissolved in the solvent, the competitive adsorption of ethanol was dominant, leading to a lower loading rate of PTX.

The adsorption of PTX on CA-CSNPs is a reversible process. As shown in Figure 6B and Table S1, when the initial PTX concentration increased from 40 to $160 \mathrm{mg} \cdot \mathrm{L}^{-1}$, the time to reach the adsorption equilibrium shortened from $300 \mathrm{~min}$ to approximately $150 \mathrm{~min}$, and the loading rate at adsorption equilibrium increased from 21.06 to $35.02 \mathrm{mg} \cdot \mathrm{g}^{-1}$; however, the encapsulation efficiency of PTX decreased from 52.65 to $21.89 \%$. From the fitting results of Langmuir (Equation (5)) and Freundlich (Equation (6)) isotherm adsorption equations in Figure 6C and Table S2, the adsorption of PTX on CA-CSNPs was more consistent with the Langmuir isotherm adsorption equation with an $R^{2}$ of 0.9974 , which indicated that the adsorption of PTX on CA-CSNPs was close to the monolayer adsorption on the ideal surface.

$$
\begin{aligned}
& \frac{C_{\mathrm{e}}}{q_{\mathrm{e}}}=\frac{1}{q_{\mathrm{m}}} \frac{1}{K_{\mathrm{L}}}+\frac{1}{q_{\mathrm{m}}} C_{\mathrm{e}} \\
& \operatorname{In} q_{\mathrm{e}}=\frac{1}{n} \operatorname{In} C_{\mathrm{e}}+\operatorname{In} K_{\mathrm{f}}
\end{aligned}
$$

where, $q_{\mathrm{e}}$ is the equilibrium adsorption capacity, $\mathrm{mg} \cdot \mathrm{g}^{-1} ; c_{\mathrm{e}}$ is the equilibrium concentration of paclitaxel, $\mathrm{mg} \cdot \mathrm{g}^{-1} ; q_{\mathrm{m}}$ is the maximum loading rate, $\mathrm{mg} \cdot \mathrm{g}^{-1} ; K_{\mathrm{L}}$ is the Langmuir adsorption coefficient, $\mathrm{L} \cdot \mathrm{mg}^{-1} ; K_{\mathrm{f}}$ is the Freundlich adsorption coefficient, $\mathrm{mg} \cdot \mathrm{g}^{-1} \cdot \mathrm{L}^{-1 / \mathrm{n}} \cdot \mathrm{mg}^{-1 / \mathrm{n}}$; and $n$ is the correlation coefficient of the binding energy. 

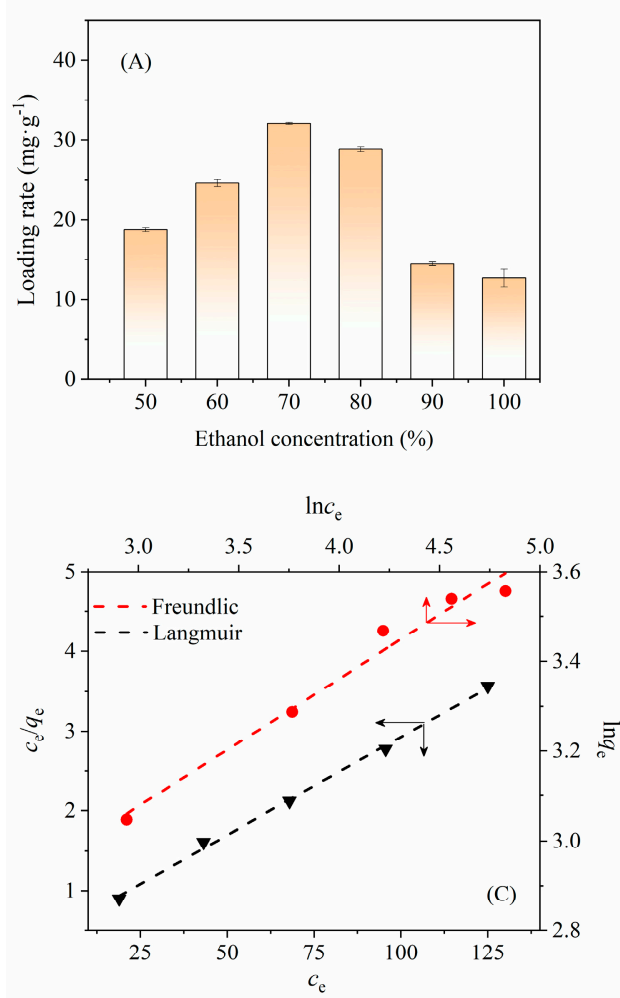
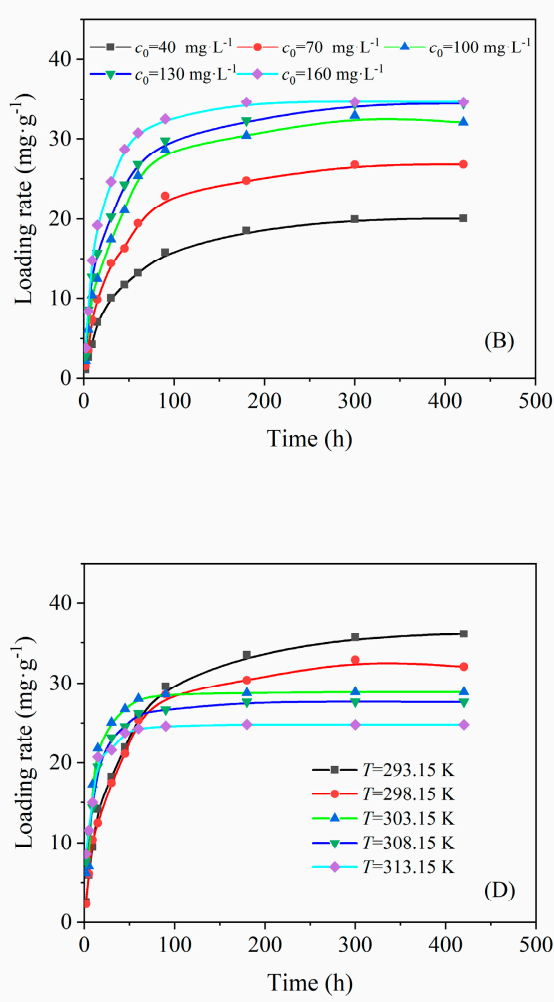

Figure 6. (A) Effects of ethanol concentration on the loading rate of CA-CSNPs $\left(c_{0}=100 \mathrm{mg} \cdot \mathrm{L}^{-1}\right.$, $T=298.15 \mathrm{~K}) ;(\mathbf{B})$ effects of the initial concentration of PTX $\left(c_{0}\right)$ on the loading rate $(T=298.15 \mathrm{~K}$, concentration of ethanol $=70 w t \%) ;(C)$ fitting curves of Langmuir and Freundlich isotherm adsorption equation; (D) effects of temperature $(T)$ on loading rate $\left(c_{0}=100 \mathrm{mg} \cdot \mathrm{L}^{-1}\right.$, ethanol concentration $\left.=70 \mathrm{wt} \%\right)$. The CA-CSNPS sample was prepared with a crosslinking agent amount of $15 w t \%$, an aqueous starch concentration of $6.0 w t \%$, an oil-water ratio of $10: 1$, a total surfactant amount of $0.20 \mathrm{~g} \cdot \mathrm{mL}^{-1}$, and a CHPTAC amount of $4.05 w t \%$. The obtained CA-CSNPs showed a diameter of $252 \mathrm{~nm}$ and an isoelectric point $(\mathrm{pI})$ of 6.89 .

As shown in Figure 6D, when the temperature decreases, the loading rate of PTX on CA-CSNPs at adsorption equilibrium increases accordingly, but it takes a longer time to reach equilibrium. When the temperature decreases from 40 to $20{ }^{\circ} \mathrm{C}$, the time to reach adsorption equilibrium is prolonged from 90 to $400 \mathrm{~min}$, while the loading rate at adsorption equilibrium increases from 24.83 to $36.14 \mathrm{mg} \cdot \mathrm{g}^{-1}$. It should be noted that the loading rate of PTX on CA-CSNPs was higher than that on polylactide-hydroxyacetic acid nanoparticles $\left(21.16 \mathrm{mg} \cdot \mathrm{g}^{-1}\right)$ [44]. As shown in Table 3 , the adsorption equilibrium constant $\left(K_{\mathrm{L}}\right.$ or $\left.K_{\mathrm{C}}\right)$ also decreases with the increasing of temperature. According to Equations (7) and (8), $\Delta H^{\circ}$ was calculated to be $-37.91 \mathrm{~kJ} \cdot \mathrm{mol}^{-1}, \Delta S^{\circ}$ was $-10.96 \mathrm{~J} \cdot \mathrm{mol}^{-1} \cdot \mathrm{K}^{-1}$, and $\Delta G^{\circ}<0$, as shown in Table 3, which suggests that the adsorption of PTX on CA-CSNPs was a spontaneous exothermic physical adsorption process and PTX was adsorbed on CA-CSNPs by van der Waals forces and hydrogen bonds between PTX molecules and starch molecules. Therefore, the loading rate would decrease with the increasing of temperature.

$$
\begin{aligned}
\ln K_{\mathrm{c}} & =-\frac{\Delta H^{\circ}}{R T}+\frac{\Delta S^{\circ}}{R} \\
\Delta G^{\circ} & =\Delta H^{\circ}-T \cdot \Delta S^{\circ}
\end{aligned}
$$

where $R$ is the universal gas constant $8.314, \mathrm{~J} \cdot \mathrm{mol}^{-1} \cdot \mathrm{K}^{-1} ; T$ is the absolute temperature, $\mathrm{K} ; K_{\mathrm{C}}$ is the thermodynamic equilibrium constant; $\Delta G^{\circ}$ is the changed Gibb's free energy, $\mathrm{J} \cdot \mathrm{mol}^{-1} ; \Delta H^{\circ}$ is the changed enthalpy, $\mathrm{J} \cdot \mathrm{mol}^{-1}$; and $\Delta S^{\circ}$ is the changed entropy, $\mathrm{J} \cdot \mathrm{mol}^{-1} \cdot \mathrm{K}^{-1}$. 
Table 3. Calculated results of thermodynamic parameters from Langmuir isotherm adsorption equation.

\begin{tabular}{|c|c|c|c|c|c|c|}
\hline$T(\mathrm{~K})$ & $\begin{array}{c}q_{\mathrm{m}} \\
\left(\mathrm{mg} \cdot \mathrm{g}^{-1}\right)\end{array}$ & $\begin{array}{c}K_{\mathrm{L}} \\
\left(\times 10^{-2} \mathrm{~L} \cdot \mathrm{mg}^{-1}\right)\end{array}$ & $K_{\mathrm{c}}\left(\times 10^{5}\right)$ & $\begin{array}{c}\Delta G^{\circ} \\
\left(\mathrm{kJ} \cdot \mathrm{mol}^{-1}\right)\end{array}$ & $\begin{array}{c}\Delta H^{\circ} \\
\left(\mathrm{kJ} \cdot \mathrm{mol}^{-1}\right)\end{array}$ & $\begin{array}{c}\Delta S^{\circ} \\
\left(\mathrm{J} \cdot \mathrm{mol}^{-1} \cdot \mathrm{K}^{-1}\right)\end{array}$ \\
\hline 293.15 & 43.99 & 6.34 & 14.77 & -34.69 & & \\
\hline 298.15 & 40.67 & 5.23 & 12.18 & -34.63 & & \\
\hline 303.15 & 39.43 & 3.82 & 8.90 & -34.58 & -37.91 & -10.96 \\
\hline 308.15 & 39.84 & 3.16 & 7.36 & -34.52 & & \\
\hline 313.15 & 37.71 & 2.36 & 5.50 & -34.47 & & \\
\hline
\end{tabular}

Note: $K_{\mathrm{c}}$ is the dimensionless adsorption equilibrium constant [45]; when the ethanol concentration is $70.0 \mathrm{wt} \%$, $K_{\mathrm{c}}=2.33 \times 10^{7} K_{\mathrm{L}}$

\subsection{Drug Release Analysis}

The release performance of PTX loaded on CA-CANPs and the comparing results of zeta potential for CA-CSNPs before and after loading drug are shown in Figure 7. As shown in Figure 7Ae, $94.19 \%$ of free PTX are released from the dialysis bag in $0.9 \%$ normal saline $(\mathrm{pH}=7)$ within $8 \mathrm{~h}$. Compared with free PTX, the release rate of PTX loaded on CA-CSNPs was $17.04 \%$ in $8 \mathrm{~h}$ and $37.61 \%$ within $96 \mathrm{~h}$ at the same condition (Figure 7Aa), which indicates that the loaded PTX has a good sustained-release effect in $0.9 \%$ normal saline at $\mathrm{pH}=7$. However, when the $\mathrm{pH}$ value of $0.9 \%$ saline decreases from 7.0 to 4.0 , the release rate of loaded PTX increases from 37.61 to $65.56 \%$ in $96 \mathrm{~h}$, which implies that PTX loaded on CA-CSNPs would have a faster release rate when it is transported to the vicinity of tumor cells because of the slightly acidic environment of tumor cells, which is consistent with the micro acid environment tested in vitro.
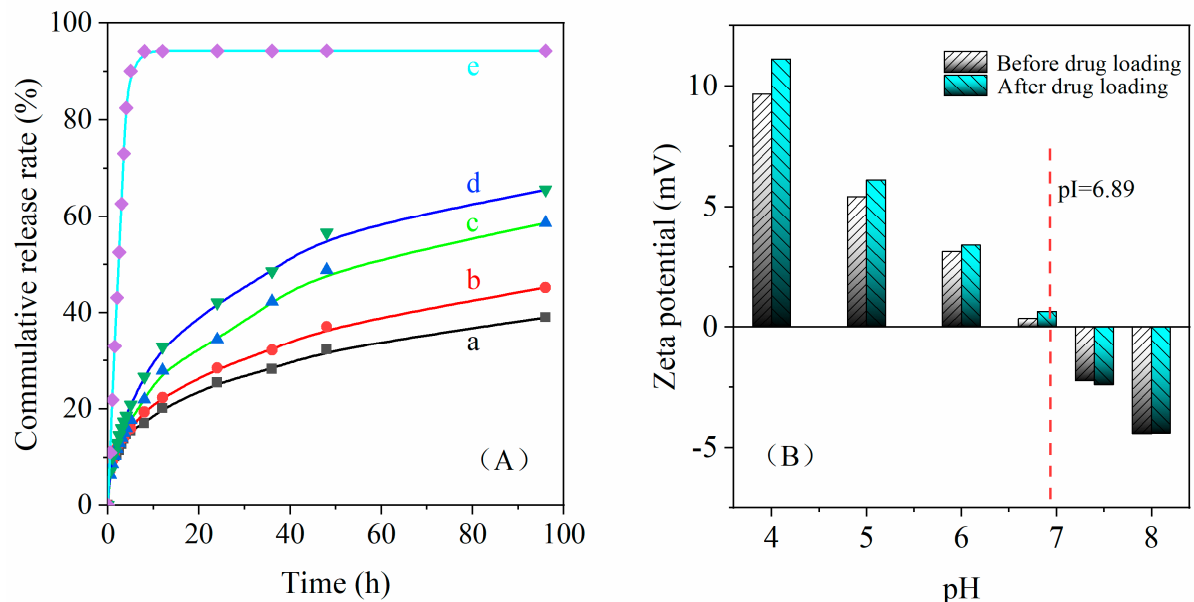

Figure 7. The release rate of PTX (A), a. PTX loaded with CA-CSNPs, $\mathrm{pH}=7.0$; b. PTX loaded with CA-CSNPs, $\mathrm{pH}=6.0$; . PTX loaded with CA-CSNPs, $\mathrm{pH}=5.0$; $\mathrm{d}$. PTX loaded with CA-CSNPs, $\mathrm{pH}=4.0$; e. Free PTX from dialysis bags, $\mathrm{pH}=7.0$; and comparing results of zeta potential for CA-CSNPs before and after loading drug (B).

As can be seen in Table S3, the release kinetics show that PTX release from CA-CSNPs was consistent with the Ritger-Peppas release kinetics (Equation (9)), and the drug release factor $(n)$ was 0.32 when the $\mathrm{pH}$ value of $0.9 \%$ normal saline was 7.0 , which suggests that the mechanism of PTX release on CA-CSNPs should be Fick diffusion rather than dissolution desorption [46], and indicates that PTX had already diffused into the carrier interior in the loading process of PTX due to the most amorphous structure of CA-CSNPs. Therefore, once the drug carrier is in the bloodstream, CA-CSNPs will effectively avoid PTX binding with blood protein to protect the physiological activity of PTX. Moreover, it will also reduce the concentration of drug diffused into blood to minimize the damage of PTX to normal cells and enrich more drugs to the target position. However, after the $\mathrm{pH}$ value of $0.9 \%$ saline decreased to 5.0, the phospholipid crosslink-bond was unstable enough to hydrolyze under acidic conditions, resulting in the fracture of the partial phospholipid crosslink-bond 
and the disintegration of nanoparticles. In this case, more PTX was delivered, and the drug release factor $(n)$ increased above 0.45 , indicating that the mechanism of PTX release had changed from Fick type to dissolution desorption. The above results suggest that the CA-CSNPs, as drug carriers of PTX, should have a slow release rate in human blood and a fast release rate in the location of tumor cells, which may meet the application requirements of targeted drug carriers [47].

$$
\frac{M_{\mathrm{t}}}{M_{\infty}}=k_{\mathrm{H}} \cdot t^{\mathrm{n}}
$$

where, $\frac{M_{\mathrm{t}}}{M_{\infty}}$ is the cumulative release rate of PTX, \%; $t$ is the release time, $\min ; k_{\mathrm{H}}$ is the release rate constant of the Rigter-Peppas release model, and $n$ is the release factor.

\subsection{Changes in Carrier Isoelectric Point of CA-CSNPs after Loading Drug}

As shown in Figure 7B, the zeta potential and isoelectric point of CA-CSNPs ( $\mathrm{pI}=6.89$ ) before and after loading PTX shows little change due to the lack of ionizable functional groups within the pharmaceutically useful range of PTX [42,48]. However, when the $\mathrm{pH}$ value was below the isoelectric point, the zeta potential of CA-CSNPs loaded with PTX was slightly higher than that of CA-CSNPs without PTX, which is due to the positive charge of secondary amino groups in PTX in an acidic environment, and thus would be beneficial to the absorption of drug carriers by tumor cells.

\section{Conclusions}

To investigate the influence of preparation conditions on the particle size of CACSNPs in the W/O microemulsion reaction system, an experimental study was performed preparing CA-CSNPs in the $\mathrm{W} / \mathrm{O}$ microemulsion reaction system with native cassava starch as a raw material, CHPTAC as a cationic agent, and $\mathrm{POCl}_{3}$ as an anionic and crosslinking agent. Degrading pretreatment of the cassava starches via acid hydrolysis is necessary to form a stable and uniform W/O microemulsion due to the larger molecular weight and greater branching degree of native cassava starch. By optimizing the reaction conditions, such as the aqueous starch concentration, the oil-water ratio, the amount of crosslinking agent, the amount of CHPTAC, the HLB value, and the amount of emulsifier, CA-CSNPs with a smooth spherical morphology and an average diameter of $252 \mathrm{~nm}$ were obtained. The anionic and cationic groups were confirmed to be introduced on the CA-CSNPs by FTIR, NMR and P element detection. The CA-CSNPs also had a charge-reversal function with $\mathrm{pH}$ response by the zeta potential test. It is worth noting that the $\mathrm{pH}$ responsive value ( $\mathrm{pI}$ ) could be controlled by adjusting the molar ratio of nitrogen to phosphorus. Moreover, the loading and release performance of the CA-CSNPs with a pI of 6.89 were evaluated by using PTX as a model drug. The loading rate of PTX reached $36.14 \mathrm{mg} \cdot \mathrm{g}^{-1}$, and the loading process was a spontaneous exothermic physical adsorption process and was consistent with the Langmuir isotherm adsorption equation. In $0.9 \%$ normal saline at $\mathrm{pH}=7.0$, the release rate was $37.61 \%$ in $96 \mathrm{~h}$, and the release process of PTX followed the Fick's desorption mechanism, which implies that PTX diffused into the interior of the CACSNPs during the drug-loading process due to the amorphous structure of approximately $95 w t \%$. However, when the $\mathrm{pH}$ value of $0.9 \%$ saline decreased, the loaded PTX had a faster release rate, i.e., a release rate of $58.65 \%$ at $\mathrm{pH}=5.0 \mathrm{in} 96 \mathrm{~h}$, which is attributed to the hydrolysis of phospholipid crosslink-bonds and the disintegration of nanoparticles under acidic conditions, and the release process changed to a dissolution-desorption mechanism. Hence, the CA-CSNPs could be used as biocompatible, biodegradable control-release carriers for antitumor drugs and have the potential for targeted drug control of tumor cells.

Supplementary Materials: The following supporting information can be downloaded at https: / / www.mdpi.com/article/10.3390/nano12040598/s1: Table S1: Effects of the initial concentration of PTX $\left(c_{0}\right)$ on the equilibrium adsorption capacity and encapsulation efficiency; Table S2: The parameter fitting results of the Langmuir and Freundlich isotherm adsorption equations; Table S3: The parameter fitting results of the Ritger-Peppas release kinetic equation. 


\begin{abstract}
Author Contributions: X.X.: funding acquisition, project administration, supervision, writingoriginal draft; Y.Z. (Youquan Zhang): formal analysis, investigation, methodology, supervision, project administration, resources, writing — review and editing; Y.Z. (Yong Zhu): investigation, methodology, writing — original draft; and Y.L.: investigation, methodology, validation. All authors have read and agreed to the published version of the manuscript.
\end{abstract}

Funding: This work was supported by the National Natural Science Foundation of China (21766001, 22168011), Guangxi Natural Science Foundation (2018GXNSFAA294073, 2018GXNSFAA281342), Dean Project of Guangxi Key Laboratory of Petrochemical Resource Processing and Process Intensification Technology (2021Z011), and special funding for 'Guangxi Bagui Scholars'.

Institutional Review Board Statement: Not applicable.

Informed Consent Statement: Not applicable.

Data Availability Statement: Not applicable.

Conflicts of Interest: There are no conflict to declare.

\title{
References
}

1. Thielemans, W.; Belgacem, M.N.; Dufresne, A. Starch nanocrystals with large chain surface modifications. Langmuir 2006, 22, 4804-4810. [CrossRef]

2. Le Corre, D.; Angellier-Coussy, H. Preparation and application of starch nanoparticles for nanocomposites: A review. React. Funct. Polym. 2014, 85, 97-120. [CrossRef]

3. Le Corre, D.; Bras, J.; Dufresne, A. Starch Nanoparticles: A Review. Biomacromolecules 2010, 11, 1139-1153. [CrossRef]

4. Kristo, E.; Biliaderis, C.G. Physical properties of starch nanocrystal-reinforced pullulan films. Carbohydr. Polym. 2007, 68, 146-158. [CrossRef]

5. Xu, C.; Chen, C.; Wu, D. The starch nanocrystal filled biodegradable poly(epsilon-caprolactone) composite membrane with highly improved properties. Carbohydr. Polym. 2018, 182, 115-122. [CrossRef]

6. Ge, S.; Xiong, L.; Li, M.; Liu, J.; Yang, J.; Chang, R.; Liang, C.; Sun, Q. Characterizations of Pickering emulsions stabilized by starch nanoparticles: Influence of starch variety and particle size. Food Chem. 2017, 234, 339-347. [CrossRef]

7. Li, J.; Yang, Y.; Lu, L.; Ma, Q.; Zhang, J. Preparation, characterization and systemic application of self-assembled hydroxyethyl starch nanoparticles-loaded flavonoid Morin for hyperuricemia therapy. Int. J. Nanomed. 2018, 13, 2129-2141. [CrossRef] [PubMed]

8. Chen, Y.; Hao, Y.; Kou, T.; Li, Q.; Gao, Q. Preparation and emulsification properties of dialdehyde starch nanoparticles. Food Chem. 2019, 286, 467-474. [CrossRef]

9. Kumari, S.; Yadav, B.S.; Yadav, R.B. Synthesis and modification approaches for starch nanoparticles for their emerging food industrial applications: A review. Food Res. Int. 2020, 128, 108765. [CrossRef] [PubMed]

10. Shi, A.; Li, D.; Liu, H.; Adhikari, B.; Wang, Q. Effect of drying and loading methods on the release behavior of ciprofloxacin from starch nanoparticles. Int. J. Biol. Macromol. 2016, 87, 55-61. [CrossRef] [PubMed]

11. El-Naggar, M.E.; El-Rafie, M.H.; El-sheikh, M.A.; El-Feky, G.S.; Hebeish, A. Synthesis, characterization, release kinetics and toxicity profile of drug-loaded starch nanoparticles. Int. J. Biol. Macromol. 2015, 81, 718-729. [CrossRef]

12. Chen, B.; Le, W.; Wang, Y.; Li, Z.; Wang, D.; Ren, L.; Lin, L.; Cui, S.; Hu, J.J.; Hu, Y.; et al. Targeting Negative Surface Charges of Cancer Cells by Multifunctional Nanoprobes. Theranostics 2016, 6, 1887-1898. [CrossRef]

13. Bae, Y.; Nishiyama, N.; Fukushima, S.; Koyama, H.; Yasuhiro, M.; Kataoka, K. Preparation and Biological Characterization of Polymeric Micelle Drug Carriers with Intracellular pH-Triggered Drug Release Property: Tumor Permeability, Controlled Subcellular Drug Distribution, and Enhanced in Vivo Antitumor Efficacy. Bioconj. Chem. 2005, 16, 122-130. [CrossRef] [PubMed]

14. Kanamala, M.; Wilson, W.R.; Yang, M.; Palmer, B.D.; Wu, Z. Mechanisms and biomaterials in pH-responsive tumour targeted drug delivery: A review. Biomaterials 2016, 85, 152-167. [CrossRef]

15. Li, S.; Huang, L.; Zhang, B.; Chen, C.; Fu, X.; Huang, Q. Fabrication and characterization of starch/zein nanocomposites with pH-responsive emulsion behavior. Food Hydrocoll. 2021, 112, 106341. [CrossRef]

16. Masoudipour, E.; Kashanian, S.; Azandaryani, A.H.; Omidfar, K.; Bazyar, E. Surfactant effects on the particle size, zeta potential, and stability of starch nanoparticles and their use in a pH-responsive manner. Cellulose 2017, 24, 4217-4234. [CrossRef]

17. Du, J.-Z.; Sun, T.-M.; Song, W.-J.; Wu, J.; Wang, J. A Tumor-Acidity-Activated Charge-Conversional Nanogel as an Intelligent Vehicle for Promoted Tumoral-Cell Uptake and Drug Delivery. Angew. Chem. Int. Ed. 2010, 49, 3621-3626. [CrossRef]

18. Mailänder, V.; Landfester, K. Interaction of Nanoparticles with Cells. Biomacromolecules 2009, 10, 2379-2400. [CrossRef] [PubMed]

19. Yang, J.; Huang, Y.; Gao, C.; Liu, M.; Zhang, X. Fabrication and evaluation of the novel reduction-sensitive starch nanoparticles for controlled drug release. Colloids Surf. B-Biointerfaces 2014, 115, 368-376. [CrossRef] [PubMed]

20. Zhang, Z.; Shan, H.; Chen, L.; He, C.; Zhuang, X.; Chen, X. Synthesis of pH-responsive starch nanoparticles grafted poly (l-glutamic acid) for insulin controlled release. Eur. Polym. J. 2013, 49, 2082-2091. [CrossRef]

21. Chang, S.-Y.; Lai, H.-M. Starch-Based Multilayer with pH-Responsive Behavior Driven by Whey Protein Concentrate: The Effect of Starch Conformation. Starch-Stärke 2020, 72, 1900277. [CrossRef] 
22. Chauhan, V.S.; Bhardwaj, N.K. Efficacy of carbohydrate polymers in filler preflocculation for use in papermaking. Arab. J. Chem. 2019, 12, 3087-3095. [CrossRef]

23. Lin, Q.; Qian, S.; Li, C.; Pan, H.; Wu, Z.; Liu, G. Synthesis, flocculation and adsorption performance of amphoteric starch Carbohydr. Polym. 2012, 90, 275-283. [CrossRef]

24. Peng, H.; Zhong, S.; Lin, Q.; Yao, X.; Liang, Z.; Yang, M.; Yin, G.; Liu, Q.; He, H. Removal of both cationic and anionic contaminants by amphoteric starch. Carbohydr. Polym. 2016, 138, 210-214. [CrossRef] [PubMed]

25. Sarmah, D.; Karak, N. Double network hydrophobic starch based amphoteric hydrogel as an effective adsorbent for both cationic and anionic dyes. Carbohydr. Polym. 2020, 242, 116320. [CrossRef]

26. Chang, R.; Tian, Y.; Yu, Z.; Sun, C.; Jin, Z. Preparation and characterization of zwitterionic functionalized starch nanoparticles. Int J. Biol. Macromol. 2020, 142, 395-403. [CrossRef] [PubMed]

27. Li, H.; Yan, S.; Mao, H.; Ji, J.; Xu, M.; Zhang, S.; Wang, J.; Liu, Y.; Sun, B. Insights into maize starch degradation by sulfuric acid from molecular structure changes. Carbohydr. Polym. 2020, 229, 115542. [CrossRef]

28. Wang, S.; Blazek, J.; Gilbert, E.; Copeland, L. New insights on the mechanism of acid degradation of pea starch. Carbohydr. Polym. 2012, 87, 1941-1949. [CrossRef]

29. Sajjadi, S.; Zerfa, M.; Brooks, B.W. Phase inversion in p-xylene/water emulsions with the non-ionic surfactant pair sorbitan monolaurate/polyoxyethylene sorbitan monolaurate (Span 20/Tween 20). Colloids Surf. A Physicochem. Eng. Asp. 2003, 218, 241-254. [CrossRef]

30. Niemann, B.; Sundmacher, K. Nanoparticle precipitation in microemulsions: Population balance model and identification of bivariate droplet exchange kernel. J. Colloid Interface Sci. 2010, 342, 361-371. [CrossRef] [PubMed]

31. Shi, A.-M.; Li, D.; Wang, L.-J.; Li, B.-Z.; Adhikari, B. Preparation of starch-based nanoparticles through high-pressure homogenization and miniemulsion cross-linking: Influence of various process parameters on particle size and stability. Carbohydr. Polym. 2011, 83, 1604-1610. [CrossRef]

32. Chen, F.; Cao, X.; Yu, J.; Su, H.; Wei, S.; Hong, H.; Liu, C. Quaternary Ammonium Groups Modified Starch Microspheres for Instant Hemorrhage Control. Colloids Surf. B Biointerfaces 2017, 159, 937-944. [CrossRef] [PubMed]

33. Xiao, S.; Liu, X.; Tong, C.; Liu, J.; Tang, D.; Zhao, L. Studies of poly-L-lysine-starch nanoparticle preparation and its application as gene carrier. Sci. China Ser. B Chem. 2005, 48, 162-166. [CrossRef]

34. Huang, Y.; Liu, M.; Gao, C.; Yang, J.; Zhang, X.; Zhang, X.; Liu, Z. Ultra-small and innocuous cationic starch nanospheres: Preparation, characterization and drug delivery study. Int. J. Biol. Macromol. 2013, 58, 231-239. [CrossRef]

35. Chang, Y.-J.; Choi, H.-W.; Kim, H.-S.; Lee, H.; Kim, W.; Kim, D.-O.; Kim, B.-Y.; Baik, M.-Y. Physicochemical properties of granular and non-granular cationic starches prepared under ultra high pressure. Carbohydr. Polym. 2014, 99, 385-393. [CrossRef]

36. Xia, H.; Li, B.-Z.; Gao, Q. Effect of molecular weight of starch on the properties of cassava starch microspheres prepared in aqueous two-phase system. Carbohydr. Polym. 2017, 177, 334-340. [CrossRef]

37. Bai, J.; Xie, X.; Li, X.; Zhang, Y. Synthesis of Octenylsuccinic Anhydride-Modified Cassava Starch in Supercritical Carbon Dioxide. Starch-Stärke 2017, 69, 1700018. [CrossRef]

38. Peng, S.; Wang, H.; Zhao, W.; Xin, Y.; Liu, Y.; Yu, X.; Zhan, M.; Shen, S.; Lu, L. Zwitterionic Polysulfamide Drug Nanogels with Microwave Augmented Tumor Accumulation and On-Demand Drug Release for Enhanced Cancer Therapy. Adv. Funct. Mater. 2020, 30, 2001832. [CrossRef]

39. Nakayama, A.; Tsuchiya, K.; Xu, L.; Matsumoto, T.; Makino, T. Drug-interaction between paclitaxel and goshajinkigan extract and its constituents. J. Nat. Med. 2021, 76, 59-67. [CrossRef]

40. Zhang, C.Y.; Chen, Q.; Wu, W.S.; Guo, X.D.; Cai, C.Z.; Zhang, L.J. Synthesis and evaluation of cholesterol-grafted PEGylated peptides with $\mathrm{pH}$-triggered property as novel drug carriers for cancer chemotherapy. Colloids Surf. B Biointerfaces 2016, 142, 55-64. [CrossRef]

41. Ringel, I.; Horwitz, S.B. Studies With RP 56976 (Taxotere): A Semisynthetic Analogue of Taxol. J. Natl. Cancer Inst. 1991, 83, $288-291$. [CrossRef] [PubMed]

42. Singla, A.K.; Garg, A.; Aggarwal, D. Paclitaxel and its formulations. Int. J. Pharm. 2002, 235, 179-192. [CrossRef]

43. Han, J.; Xiao, J.; Wang, H.; Chang, H.; Ma, P. Measurement and correlation of taxol solubility in methanol, ethanol and methanol-water systems. CIESC J. Chem. Ind. Eng.-China 2001, 52, 64-67.

44. Sharma, N.; Kumari, R.M.; Gupta, N.; Syed, A.; Bahkali, A.H.; Nimesh, S. Poly-(Lactic-co-Glycolic) Acid Nanoparticles for Synergistic Delivery of Epirubicin and Paclitaxel to Human Lung Cancer Cells. Molecules 2020, 25, 4243. [CrossRef]

45. Lima, E.C.; Hosseini-Bandegharaei, A.; Moreno-Piraján, J.C.; Anastopoulos, I. A critical review of the estimation of the thermodynamic parameters on adsorption equilibria. Wrong use of equilibrium constant in the Van't Hoof equation for calculation of thermodynamic parameters of adsorption. J. Mol. Liq. 2019, 273, 425-434. [CrossRef]

46. Pentak, D.; Maciążek-Jurczyk, M.; Zawada, Z.H. The role of nanoparticles in the albumin-cytarabine and albumin-methotrexate interactions. Mater. Sci. Eng. C 2017, 73, 388-397. [CrossRef] [PubMed]

47. Qiu, C.; Wang, C.; Gong, C.; McClements, D.J.; Jin, Z.; Wang, J. Advances in research on preparation, characterization, interaction with proteins, digestion and delivery systems of starch-based nanoparticles. Int. J. Biol. Macromol. 2020, 152, 117-125. [CrossRef]

48. Fonseca, C.; Simões, S.; Gaspar, R. Paclitaxel-loaded PLGA nanoparticles: Preparation, physicochemical characterization and in vitro anti-tumoral activity. J. Control Release 2002, 83, 273-286. [CrossRef] 